\title{
Evaluation of Therapeutic Efficiency of Hilsha Fish Oil on Cardiovascular Disease and Hepatic Disease Marker in Hypercholesterolemic Mice
}

\author{
Munira $\mathbf{S}^{1}$, Asaduzzaman $\mathbf{M}^{1}$, Sohanur Rahman $\mathbf{M}^{1}$, Muedur Rahman $\mathbf{M}^{1}$, Hasan $\mathbf{M}^{2}$, Biswas $\mathbf{S}^{3}$, Islam $\mathbf{M}^{1}$, Mamun $\mathbf{M A}{ }^{1}$, Khan $\mathbf{M} \mathbf{M H}^{1}$, Rahman
} $M^{1}{ }^{1}$, Karim MR ${ }^{1}$ and Islam MA ${ }^{1 *}$

${ }^{1}$ Department of Biochemistry and Molecular Biology, University of Rajshahi, Rajshahi-6205, Bangladesh

${ }^{2}$ Department of Biophysical Chemistry, Kyoto Pharmaceutical University, 5 Nakauchi-cho, Misasagi, Yamashina-Ku, Kyoto 607-8414, Japan

${ }^{3}$ Department of systems Neurophysiology, Graduate school of medical and dental science, Tokyo Medical and Dental University, Tokyo, Japan

\begin{abstract}
Hypercholesterolemia is a clinical situation characterized by the elevated serum cholesterol and associated with the higher risk of cardiovascular disease (CVD), hypertension and stroke. This study aimed to evaluate the therapeutic efficiency of hilsha fish (Tenualosa ilisha) oil on diet-induced hypercholesterolemic (HC) albino mice. Mice were divided in three groups consisting each of six mice : control group, $\mathrm{HC}$ control group (fed the basal diet containing $1.5 \%$ cholesterol and $0.5 \%$ cholic acid) and the other group of mice fed the same previous hypercholesterolemic diet supplemented with hilsha fish oil (HFO) $5 \%$. Serum lipid profile (total cholesterol-TC, low density lipoprotein-LDL, high density lipoprotein$\mathrm{HDL}$, triglyceride-TG and very low density lipoprotein-VLDL) were determined using commercial kits. After treatment with HFO a potential antilipidemic effect was observed as TC, TG, LDL, VLDL showed significant $(p<0.001)$ decrease whereas HDL showed significant increase $(p<0.001)$ compared to the HC control group. The SGPT, SGOT and CRP were also significantly decrease $(p<0.001)$. Therefore HFO might have hepatoprotective activity. Regarding liver tissue extract, the levels of total cholesterol and triglyceride were decreased significantly in treated mice. Gas chromatography (GC)-MS analysis of HFO showed that it contained a high amount of poly unsaturated fatty acids (PUFA) especially EPA and DHA. These Omega-3 fatty acids have an indicative effect to reduce the risk of CVD and other chronic diseases. From the above findings, it can be concluded that HFO has a potential benefit in the treatment of CVD and play a role in its management as well as in reducing the risk of CVD associated hepatic complications.
\end{abstract}

Keywords: Hypercholesterolemia; CVD; Lipid profile; CRP; EPA; DHA

Abbreviations: Hilsha Fish Oil (HFO); Hypercholesterolemic (HC); Atherogenic Index (AI); Cardiovascular Disease (CVD); Eicosapentaenoic Acid (EPA); Docosahexaenoic Acid (DHA); Serum Glutamic Pyruvic Transaminase (SGPT); Serum Glutamic Oxaloacetic Transaminase (SGOT); Coronary Heart Disease (CHD)

\section{Introduction}

Hypercholesterolemia, also called dyslipidemia is the presence of high levels of cholesterol in the blood. Hypercholesterolemia has been considered as a major risk factor for coronary heart disease (CHD) and atherosclerosis. Hyperlipidemia, particularly elevated serum cholesterol and Low-Density Lipoprotein (LDL) levels, responsible for the development of atherosclerotic heart disease [1]. Hypercholesterolemia is a major problem to many societies especially the health professionals because of the close correlation between cardiovascular diseases (CVD) and lipid abnormalities [2,3]. Dietary factors such as continuous ingestion of high amounts of saturated fats and cholesterol are believed to be directly related to hypercholesterolemia and susceptibility to atherosclerosis [4]. Clinical trials have demonstrated that intensive reduction of plasma low density lipoprotein (LDL) levels could reverse atherosclerosis and decrease the incidence of cardiovascular diseases [5]. It is believed that hypercholesterolemia is correlated to elevated sugar level and hepatic problems.

Tenualosa ilisha (Hilsha) belongs to subfamily Alosinae, family Clupeidae, order Clupeiformes, is one of the most important tropical fishes of the Indo-Pacific region. Hilsha fish contain a high amount of protein, minerals, vitamins as well as polyunsaturated fatty acids (PUFAs). Many studies have been conducted on support of various effects of fish oil. It is suggested that fish oil contain long chain polyunsaturated fatty acid [6] more specifically eicosapentaenoic acid
(EPA) and docosahexaenoic acid (DHA) which have a great benefit for cardiac health [7] ,controlling blood glucose [8] reduction of arterial disease [9]. Fish oil containing $\omega-3$ PUFAs is more effective than the vegetable oil ( $\omega-6$ PUFAs) in reduction of lipid profile in human [10]. Docosahexaenoic acid ( $\omega-6$ PUFA) is more effective in lowering serum cholesterol level of experimentally induced hypercholesterolemic rats [11]. Epidemiological studies also show that eating fish or vegetable oil concurrently decreases blood cholesterol and LDL levels and increases HDL, and thus reduces the risk of coronary death $[12,13]$. Thus fish has medicinal and therapeutic value [14]. Many studies revealed that hilsha fish oil (HFO) can reduce blood glucose and insulin level in diabetes induced rats. Hilsha fish oil can also decrease non-esterified fatty acids (NEFA), platelet aggregation and increase total anti-oxidant status [15].

Previous studies showed that long chain $\mathrm{n}-3$ polyunsaturated fatty acid in fish reduced CHD mortality [16] and cardiovascular risk factors like serum triglyceride (TG) concentration, blood pressure, arrhythmias and inflammation [17]. However there is no

${ }^{*}$ Corresponding author: Dr. Mohammad Amirul Islam, Department of Biochemistry and Molecular Biology, University of Rajshahi, Rajshahi-6205, Bangladesh, Fax: +88-0721-750064; Tel: +88-0721-750049/4109; E-mail: maislam06@gmail.com

Received July 27, 2015; Accepted September 30, 2015; Published October 07, 2015

Citation: Munira S, Asaduzzaman M, Sohanur Rahman M, Muedur Rahman M, Hasan M, et al. (2015) Evaluation of Therapeutic Efficiency of Hilsha Fish Oil on Cardiovascular Disease and Hepatic Disease Marker in Hypercholesterolemic Mice. Biol Med (Aligarh) 7: 254. doi: 10.4172/0974-8369.1000254

Copyright: ( $) 2015$ Munira S, et al. This is an open-access article distributed under the terms of the Creative Commons Attribution License, which permits unrestricted use, distribution, and reproduction in any medium, provided the original author and source are credited. 
Citation: Munira S, Asaduzzaman M, Sohanur Rahman M, Muedur Rahman M, Hasan M, et al. (2015) Evaluation of Therapeutic Efficiency of Hilsha Fish Oil on Cardiovascular Disease and Hepatic Disease Marker in Hypercholesterolemic Mice. Biol Med (Aligarh) 7: 254. doi: 10.4172/0974-8369.1000254

Page 2 of 5

sufficient evidence of decreasing cholesterol level by consuming HFO in experimental animals. The aim of the present study is to investigate the effect of HFO on serum lipid profile and on hepatic disease marker of experimentally induced HC mice.

\section{Material and Methods}

\section{Collection of hilsha fish}

Tenualosa ilisha is essentially a marine water fish but it is abundantly found in the big and small rivers of Bangladesh. 3-5 fishes were collected from Padma River for this study. After collection fishes were cut into small pieces (about $15-20 \mathrm{~g}$ of weight) and sun dried at temperature $40-42^{\circ} \mathrm{C}$ for 6 hours to completely remove moisture from it.

\section{Extraction of oil}

Oil was extracted from the dried fish material with n-hexane by Soxhlet apparatus according to [18]. The extract was evaporated under reduced pressure in a rotary evaporator to obtain the oil.

\section{GC mass analysis of fatty acids in hilsha fish oil}

Fatty acid composition of extracted oil was determined by Gasliquid chromatography according to [19]. Gas chromatography was conducted with a Gas Chromatograph GC-2025 series with AOC-20i Auto Injector (Shimadzu Co, Japan). GC- 2025 Gas chromatography status include temperature $-280^{\circ} \mathrm{C}$, pressure- $175.4 \mathrm{KPa}$, total flow$165 \mathrm{ml} / \mathrm{min}$, purge flow- $3 \mathrm{ml} / \mathrm{min}$, column temperature- $270^{\circ} \mathrm{C}$. Hilsha fish oil was first saponified to produce the free fatty acid salts. The fatty acid salts then are derivatized to form the fatty acid methyl esters (FAME) according to the American Oil Chemists Society (AOCS). The FAME was extracted with a non-polar solvent (e.g., hexane) for analysis by GC.

Each FAME (Fatty Acid Methyl Ester) in extract was identified by comparing retention times with those of known standard FAME (Lipid Standard Sigma chemical Co, St Louis, MO, USA).The area of fatty acids was measured with GC solution 2011. The results were expressed as relative percentage of fatty acids. The relative percentage of fatty acids was calculated by the formula:

$$
\text { Relative percentage of fatty acid }=\frac{\text { Area of fatty acid } \times 100}{\text { Total area of detected fatty acids }}
$$

\section{Experimental animals and treatment}

Albino mice weighing ranged (24-26 g) were purchased from the Animal House of International Centre for Diarrheal Disease and Research, Bangladesh (ICDDRB), Dhaka, Bangladesh. They were adapted for one week before the experiment. All the animals were kept and maintained under laboratory conditions of temperature (22 $\pm 72^{\circ} \mathrm{C}$ ), humidity $(45.75 \%)$ and $12 \mathrm{~h}$ day: $12 \mathrm{~h}$ night cycle; and were allowed free access to food (standard pellet diet) and water ad libitum.

The animals were divided into three groups containing six mice $(\mathrm{n}=6)$ in each and divided into following groups:

Group 1 (G1): Control mice; fed basal diet according to [20].

Group 2 (G2): Hypercholesterolemic mice, fed the basal diet + $1.5 \%$ cholesterol $+0.5 \%$ cholic acid according to [21]

Group 3 (G3): Treated mice; fed hypercholesterolemic (HC) diet supplemented with $5 \%$ hilsha fish oil (HFO).

Body weight of mice was measured at the initial and final day of the experiment of 6 weeks. At the end of experimental period (6 weeks), mice were sacrificed after overnight fasting. Mice were anesthetized with diethyl ether $(1.9 \%)$ and blood was collected from the heart. The blood samples were left for 15 minutes at room temperature and then centrifuged at $3000 \mathrm{rpm}$ for 20 minutes to separate the serum, then kept in plastic vials at $-20^{\circ} \mathrm{C}$ until analysis. Main organs such as liver, heart and kidney were carefully separated and washed with cold saline and dry on filter paper and the weight were recorded. Liver tissues were quickly dissected, rinsed in ice-chilled normal saline, blotted on filter paper. The tissues were cut into small portions and stored at $-20^{\circ} \mathrm{C}$ until using for measuring cholesterol and triglyceride contents. Ethical guideline was maintained in animal handling during the study and permission was obtained from the concerned department.

\section{Biochemical Analysis}

Serum lipid profile such as triglyceride, total cholesterol, HDLcholesterol, Very Low Density Lipoprotein were measured using quantification kits (Linear chemicals, Barcelona, Spain) by automatic Bioanalyzer (Hitachi 7180, Hitachi, Tokyo, Japan). Serum LDL was determined according to the Friedewald formula with use of HDL and total cholesterol value. Hepatic enzymes such as SGPT and SGOT as well as CRP were also measured using quantification kits. Atherogenic index (AI) and HTR ratio was calculated by an equations development by Friedewald [22].

Atherogenic index $(\mathrm{AI})=($ serum total cholesterol $-\mathrm{HDL}-\mathrm{c}) /$ HDL-c

\section{HTR ratio $=$ HDL-c/TC $x 100$}

\section{Extraction and analysis liver total cholesterol and triglyceride}

Estimation of total cholesterol and triglycerides from liver extract was carried out according to [23]. $1 \mathrm{~g}$ of liver portion from each animal was homogenized in $10 \mathrm{ml}$ 2-propanol. The liver homogenate was allowed to stand for $48 \mathrm{~h}$ at $4^{\circ} \mathrm{C}$. The mixture was centrifuged $15 \mathrm{~min}$ at $2500 \mathrm{rpm}$ and the supernatant was used for lipid analysis. Total cholesterol and triacylglycerol were quantified enzymatically as described above.

\section{Results}

Fatty acid composition of hilsha fish oil (HFO) was illustrated in Table 1. These data revealed that HFO contain $34.14 \%$ total saturated fatty acid (TSFA), $22.81 \%$ mono unsaturated (MUFAs) and $15.19 \%$ polyunsaturated fatty acids (PUFAs). Among those fatty acids, palmitic acid (C16:0) 25.17\%, oleic acid (C18:1) 22.81\% and eicosapentaenoic acid (C20:5) 7.01\% accounted the highest proportions of fatty acid.

Data in Table 2 showed the changes of lipids profile in different group of mice. These data viewed that in hypercholesterolemic mice (HC) group TC, TG,VLDL and LDL-c concentration increased significantly $\mathrm{P}<0.001$ whereas level of good cholesterol HDL-c significantly decreased compared to healthy control group. Serum TC, TG, VLDL and LDL-c level of HFO treated HC mice decreased by $30.94 \%, 65.90 \%, 42.77 \%$ and $13.65 \%$ respectively whereas HDL-c increased $64.00 \%$.

Data in Table 3 depicted the initial and final body weight as well as body weight gain after the treatment period. These data revealed that there is less increase in body weight in HC mice group. On the other hand by treatment with HFO body weight gain was decreased by $5.59 \%$.

In Table 4, the results was indicated the effect of HFO on AI, 
Citation: Munira S, Asaduzzaman M, Sohanur Rahman M, Muedur Rahman M, Hasan M, et al. (2015) Evaluation of Therapeutic Efficiency of Hilsha Fish Oil on Cardiovascular Disease and Hepatic Disease Marker in Hypercholesterolemic Mice. Biol Med (Aligarh) 7: 254. doi: 10.4172/0974-8369.1000254

Page 3 of 5

\begin{tabular}{|l|c|c|}
\hline \multirow{4}{*}{ Items } & Formula & Hilsha fish oil \\
\hline \multirow{3}{*}{ Saturated fatty acids (SFA) } & $\mathrm{C} 14: 1$ & 2.45 \\
\cline { 2 - 3 } & $\mathrm{C} 16: 0$ & 25.17 \\
\cline { 2 - 3 } & $\mathrm{C} 16: 1$ & 1.65 \\
\cline { 2 - 3 } & $\mathrm{C} 18: 0$ & 4.19 \\
\cline { 2 - 3 } Total saturated fatty acid (TSFA) & $\mathrm{C} 22: 0$ & 0.68 \\
\hline Monounsaturated fatty acid (MUFA) & $\mathrm{C} 18: 1$ & 34.14 \\
\hline \multirow{2}{*}{ Omega-6 } & $\mathrm{C} 18: 2$ & 1.43 \\
\hline \multirow{3}{*}{ Omega-3 } & $\mathrm{C} 20: 4$ & 0.40 \\
\hline Total Polyunsaturated fatty acid (PUFA) & $\mathrm{C} 18: 3$ & 3.42 \\
\hline
\end{tabular}

hypercholesterolemic mice group than the normal control mice which was declined significantly $(\mathrm{P}<0.001)$ by $32.35 \%$ with $\mathrm{HFO}$ supplementation (Figure 2).

\section{Discussion}

Two important groups of PUFA in human nutrition are the omega-6 and omega-3 fatty acids. Many studies have shown EPA and DHA are beneficial to our heart system and have protective effects for different diseases. A study showed that the percentage of polyunsaturated fatty acids (PUFA) in halibut, mackerel, bloater and sprat were $31.9 \%, 45.4 \%, 40.8 \%$ and $37.0 \%$ respectively [24]. These marine fishes also have cholesterol lowering effect.Omega-3 fatty acids have TG-lowering effect that may be mediated by inhibition of the soluble phosphatidate phosphohydrolase and the effect on serum cholesterol may be partly due to inhibition of HMG-CoA reductase which is the rate-limiting enzyme in cholesterol biosynthesis [25]. Omega-3 fatty acids also improve hepatic steatosis in mice and may be used to increase the pool of potential live liver donors that are currently excluded because of the presence of macrovesicular steatosis [26]. Hilsha fish oil effectively reduced serum lipid profile level and this finding was found consistent as reported by others. Dietary marine fish oil reduced blood cholesterol in the experimentally induced hypercholesterolemic rats [27]. Anti cholesterolemic effects of Hilsha fish oil was also reported in streptozotocin-treated diabetic rats [15]. It has been suggested that the longer lifespan of Japanese and Nordic populations may be partially due to their higher consumption of fish and seafood. A study showed that after 10 months of eating $100 \mathrm{~g}$ hilsa fish per day, serum total cholesterol level fell from 285.1 to $244.6 \mathrm{mg} / \mathrm{dl}$ (14.2\% decrease) in the hypercholesterolemic subjects [28]. Induction of hypercholesterolemia significantly increased body weight of experimental mice. This result was supported by a finding which reported that rats fed high cholesterol diet showed significant increase in body weight gain [29]. But feeding diet containing HFO decreases body weight compared with HC mice. This occurs may be due to the catabolism of lipid accumulated in adipose tissue causing a decrease in body weight. HFO also showed significant effect on AI, LDL-C/HDL-C Ratio and HTR\%. Reduction in HTR ratio is important

LDL-C/HDL-C Ratio and HTR in hypercholesterolemic mice. Atherogenic index and LDL-C/HDL-C ratio increased markedly while $\mathrm{HTR} \%$ decreased in the HC group. But by treating HC mice with HFO supplementation AI and LDL-C/HDL-C ratio reduced to 21.32 and 20.78 respectively and HTR\% elevated to 4.48 .

Lipid level of liver tissue was viewed in Table 5. High cholesterol diet caused significant increase $\mathrm{p}<0.001$ of hepatic cholesterol $(50.00 \%)$ and triacylglycerol $(52.55 \%)$ compared to the healthy control group. Administration hypercholesterolemic diet supplemented with HFO reduced hepatic TC and TG by $13.91 \%$ and $16.10 \%$ respectively.

Effect of HFO on the weight of main organs of HC mice was represented in (Table 6). Results revealed that liver weight was markedly increased in mice fed hypercholesterolemic diet compared to normal control group. Meanwhile, there was no change in the weight of other organs. Supplemented diet of HC mice with 5\% HFO reduced liver weight compared to $\mathrm{HC}$ group.

There was a significant $(\mathrm{P}<0.001)$ increase of SGPT and SGOT level after induction of hypercholesterolemia which was decreased by HFO significantly $(\mathrm{P}<0.001)$. SGPT level increased by $70.25 \%$ in HC group and decreased by $23.77 \%$ with HFO supplementation. Moreover treatment with HFO decreased SGOT level by $30.87 \%$. This result was illustrated in (Figure 1).

C - Reactive protein (CRP) level was also higher in

\begin{tabular}{|c|c|c|c|}
\hline Groups & Al & LDL/HDL Ratio & HTR Ratio \\
\hline G1 control & $17.33 \pm 0.87$ & $15.1 \pm 1.56$ & $5.45 \pm 0.34$ \\
\hline G2 (HC) & $52.23 \pm 2.12^{*}$ & $39.64 \pm 2.34^{*}$ & $1.88 \pm 0.45^{*}$ \\
\hline G3 (HC)+ fish oil & $21.32 \pm 1.09^{* *}$ & $20.78 \pm 1.76^{* *}$ & $4.48 \pm 0.37^{\star \star}$ \\
\hline
\end{tabular}

Atherogenic index; ${ }^{*}$ vs control group, ${ }^{* *}$ vs hypercholesterolemic control.

Table 4: Levels of AI, LDL/HDL Ratio and HTR of different group of mice Mean \pm SD.

\begin{tabular}{|c|c|c|}
\hline Groups & TC $($ Mean \pm SD) & TG (Mean \pm SD) \\
\hline G1 control & $2.06 \pm 0.25$ & $11.97 \pm 0.60$ \\
\hline G2 $(H C)$ & $3.09 \pm 0.53^{\mathrm{b}^{*}}$ & $18.26 \pm 0.68^{\mathrm{a}^{*}}$ \\
\hline G3 $(\mathrm{HC})+$ fish oil & $2.66 \pm 0.76^{* *}$ & $15.32 \pm 0.63^{\mathrm{a}^{* *}}$ \\
\hline
\end{tabular}

Total cholesterol (TC), Triacylglycerol (TG). a: $\mathrm{P}<0.001 ; \quad \mathrm{b}<0.05 ; \quad$ * vs control group, ${ }^{* *}$ vs hypercholesterolemic control

Table 5: Levels of total cholesterol, triglyceride in liver tissue in different group of mice liver (mg/g, wet liver).

\begin{tabular}{|c|c|c|c|}
\hline Groups & Liver & Heart & Kidney \\
\hline G1 control & $2.15 \pm 0.03$ & $0.18 \pm 0.01$ & $0.195 \pm 0.01$ \\
\hline G2 $(\mathrm{HC})$ & $2.61 \pm 0.04^{\mathrm{a}^{\star}}$ & $0.20 \pm 0.004^{\star}$ & $0.206 \pm 0.01^{*}$ \\
\hline G3 (HC)+ fish oil & $2.03 \pm 0.07^{\mathrm{a}^{* *}}$ & $0.15 \pm 0.002^{\mathrm{a}^{*}}$ & $0.196 \pm 0.01^{* *}$ \\
\hline
\end{tabular}

a: $\mathrm{P}<0.001$; * vs control group, ** vs hypercholesterolemic control

Table 6: Changes of weight of organs different group of mice $(g)$ Mean \pm SD. 
Citation: Munira S, Asaduzzaman M, Sohanur Rahman M, Muedur Rahman M, Hasan M, et al. (2015) Evaluation of Therapeutic Efficiency of Hilsha Fish Oil on Cardiovascular Disease and Hepatic Disease Marker in Hypercholesterolemic Mice. Biol Med (Aligarh) 7: 254. doi: 10.4172/0974-8369.1000254

Page 4 of 5

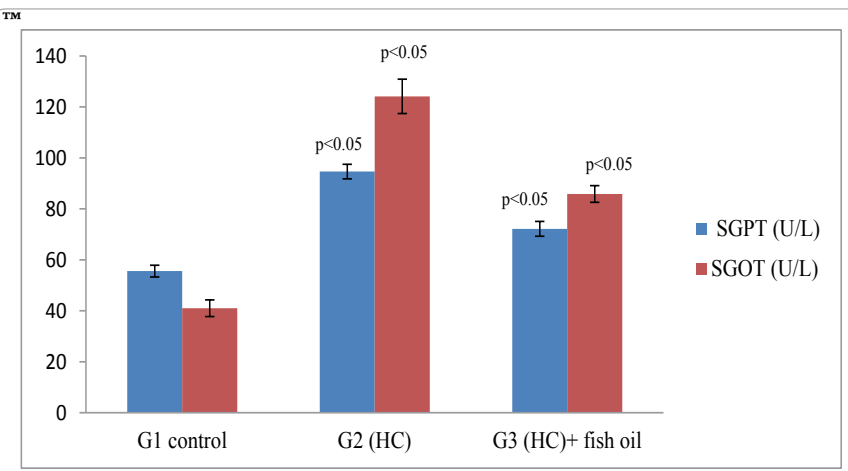

Figure 1: Effect of hilsha fish oil on serum SGPT and SGOT of experimenta mice.

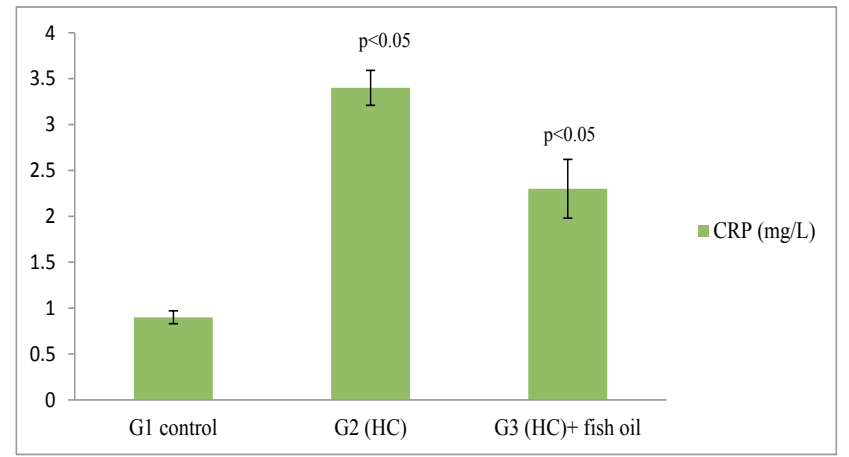

Figure 2: Effect of hilsha fish oil on serum CRP of experimental mice.

in predicting coronary heart disease in human being, an increase in this ratio is believed to furnish a beneficial effect. This result was supported by another experiment who stated that the increase in HDL-C or HTR ratio is one of the most important criteria of anti-hypercholesterolemic agent [30]. Supplementation of HFO also significantly decreased liver cholesterol and triglyceride level. Animal-derived Hilsha ilisha fish oil is more effective in reducing the serum and liver cholesterol than soybean and palm oil, though both soybean and palm oil are also effective in reducing serum and liver cholesterol [31]. Weight of liver in $\mathrm{HC}$ mice increased significantly $(\mathrm{p}<0.001)$ which was compensated by treatment with HFO. The increase in hepatic enzymes SGPT and SGOT in hypercholesterolemic mice indicate dysfunctions of liver. On the other hand supplementation of HFO significantly decreased the level of these enzymes indicate effective recovery of the hepatic function by improvement of lipid metabolism or delaying the hepatic disease.C- Reactive Protein (CRP) is a simple cost effective test, which can predict the cardiovascular risk. The addition of CRPtesting to standard lipid screening appears to provide an important method to determine Cardiovascular Disease (CVD) risk factor [32]. Dietary supplementation of HFO declined CRP level significantly and thus reduced the risk of cardiovascular diseases.

\section{Statistical Analysis}

The assays were carried out in triplicate, and the results were expressed as mean values and the standard deviation (SD). Results were analyzed by using Scientific Package of Social Science (SPSS) version 17.0. The descriptive statistic was used to analyze mean, standard deviation where by analytical statistics, one-way ANOVA was used to determine statistical significance $(\mathrm{p}<0.05)$ among the groups.

\section{Conclusion}

There is considerable evidence from experimental studies that hilsha fish oil has significant benefit in the management of hypercholesterolemia. This anti lipidemic effect is due to the presence of omega-3 fatty acids that inhibit enzymes in lipid biosynthetic pathway. Hilsha fish oil also reduced SGPT, SGOT and CRP level so it may have hepatoprotective activity. Therefore these results indicate that hilsha fish oil have important implication in the management of hypercholesterolemia as well as cardiovascular and hepatic complications.

\section{Acknowledgements}

The financial supported was given by National Science and Technology (NST), under the ministry of education Bangladesh and Faculty of Science Rajshahi University, Rajshahi-6205, Bangladesh.

\section{References}

1. Corral AR, Somers VK, Korinek J, Johnson JS, Thomas RJ, et al. (2006) Update in prevention of atherosclerotic heart disease: management of major cardiovascular risk factor. Revista de Investigations Clinica 58: 237-244.

2. Ramachandran HD, Narasimhamurthy K, Raina PL (2003) Modulation of Cholesterol induced hypercholesterolemia through dietary factors in Indian desert gerbils (Merioneshurriace). Nutrition Res 23: 245-256.

3. Matos SLH, Paula ML, Pedrosa, RC, Santos EL, Oliveia JD, et al. (2005) Dietary Models for inducing Hypercholesterolemia in rats. Brazilian Arc Biol Technol 48: 203-209.

4. Asahina M, Sato M, Imaizumi K (2005) Genetic analysis of diet-induced hypercholesterolemia in exogenously hypercholesterolemic rats. J Lipid Res 46: 2289-2294

5. Ichihashi T, Izawa M, Miyata K, Mizui T, Hirano K, et al. (1998) Mechanism of hypocholesterolemic action of S-8921 in rats: S-8921 inhibits ileal bile acid absorption. J Pharmacol Exp Ther 284: 43-50.

6. Kris-Etherton PM, Harris WS, Appel LJ (2002) American Heart Association Nutrition Committee. (2002) Fish consumption, fish oil, omega-3 fatty acids and cardiovascular disease. Circulation 106: 2747-2757.

7. Kromhout D, Feskens EJ, Bowles CH (1995) The protective effect of a small amount of fish on coronary heart disease mortality in an elderly population. Int J Epidemiol 24: 340-345.

8. Nettleton JA, Katz R (2005) n-3 long-chain polyunsaturated fatty acids in type 2 diabetes: a review. J Am Diet Assoc 105: 428-440.

9. Hornstra G (1989) The significance of fish and fish-oil enriched food fo prevention and therapy of ischaemic cardiovascular disease. Vergroesen, $\mathrm{E}$. G. eds. The Role of Fats in Human Nutrition Academic Press New York, NY.

10. Endres S, DeCaterina R, Schmidt EB, Kristensen D (1995) n-3 Polyunsaturated fatty acids: update. Eur J Clin Invest 25:629-38 Grove T H.(1979). Effect of reagent $\mathrm{pH}$ on the determination of $\mathrm{HDL}$ Cholesterol by precipitetion with sodium phosphotungstate-magnesium. Clinchem 25:560-564.

11. Kobatake Y, Kuroda K, Jinnouchi H, Nishide E, Innami S (1984) Differentia effects of eicosapentaenoic acid and decosahexaenoic fatty acids on lowering of triglyceride and cholesterol levels in the serum of rats on Hypercholesterolemic diet. J Nutr Sci Vitaminol 30:357-372.

12. Yamori Y, Nara Y, Iritani N, Workman RJ, Inagami T (1985) Comparison of serum phospholipid fatty acids among fishing and farming Japanese populations and American inlanders. J Nutr Sci Vitaminol (Tokyo) 31: 417-422.

13. Dyerberg J, Bang HO, Hjorne N (1975) Fatty acid composition of the plasma lipids in Greenland Eskimos. Am J Clin Nutr 28: 958-966.

14. Mohanty BP, Sudheesan D, Sankar TV, Das MK, Sharma AP (2011a) Therapeutic value of fish. Bulletin No. 170, Central Inland Fisheries Research Institute (ICAR), Barrackpore, India.

15. Mahmud I, Hossain A, Hossain S, Hannan A, Ali L, et al. (2004) Effects of Hilsa ilisa fish oil on the atherogenic lipid profile and glycaemic status of streptozotocin-treated type 1 diabetic rats. Clin Exp Pharmacol Physiol 31 : 76-81. 
Citation: Munira S, Asaduzzaman M, Sohanur Rahman M, Muedur Rahman M, Hasan M, et al. (2015) Evaluation of Therapeutic Efficiency of Hilsha Fish Oil on Cardiovascular Disease and Hepatic Disease Marker in Hypercholesterolemic Mice. Biol Med (Aligarh) 7: 254. doi: 10.4172/0974-8369.1000254

Page 5 of 5

16. Wang C, Harris WS, Chung M, Lichtenstein AH, Balk EM, et al. (2006) n-3 fatty acids from fish or fish-oil supplements, but not alpha-linolenic acid benefit cardiovascular disease outcomes in primary-and secondary-prevention studies: A systematic review. Am J Clin Nutr 84:5-17.

17. Calder PC (2004) n-3 Fatty acids and cardiovascular disease: evidence explained and mechanisms explored. Clin Sci (Lond) 107: 1-11.

18. Bahl BS, Bahl A (2001) In: Advanced Organic Chemistry, S. Chand and. Co. Ltd. India.

19. Stoffer W, Florence CHU, Ahrens E (1959) Analysis of long chain fatty acids by Gas Liquid Chromatography. Anal Chem. 31: 307-308.

20. Reeves PG, Nielsen FH, Fahey GC Jr (1993) AIN-93 purified diets for laboratory rodents: final report of the American Institute of Nutrition ad hoc writing committee on the reformulation of the AIN-76A rodent diet. J Nutr 123: 1939-1951.

21. Rahman MM, Mazid MA, Islam SN (2014) Hypocholesterolemic Effects of Fish and Vegetable Oils on the Serum Lipid Profile of Experimentally Induced Hypercholesterolemic Rats. Eur Sci J 10:1-8.

22. Friedewald WT, Levy RI, Fredrickson DS (1972) Estimation of the concentration of low-density lipoprotein cholesterol in plasma, without use of the preparative ultracentrifuge. Clin Chem 18: 499-502.

23. Haug A, Høstmark AT (1987) Lipoprotein lipases, lipoproteins and tissue lipids in rats fed fish oil or coconut oil. J Nutr 117: 1011-1017.

24. Regulska-llow B, llow R, Konikowska K, Kawicka A, Rózańska D, et al. (2013) Fatty acid profile of the fat in selected smoked marine fish. Rocz Panstw Zakl Hig 64: 299-307.
25. al-Shurbaji A, Larsson-Backström C, Berglund L, Eggertsen G, Björkhem (1991) Effect of $n-3$ fatty acids on the key enzymes involved in cholesterol and triglyceride turnover in rat liver. Lipids $26: 385-389$.

26. Alwayn IP, Andersson C, Zauscher B, Gura K, Nose V, Puder M (2005) Omega-3 fatty acids improve hepatic steatosis in a murine model: potentia implications for the marginal steatotic liver donor. Transplantation 79:606-608.

27. Nicolaysen R, Regard R (1961) Effects of various oils and fats on serum Cholesterol in experimental hypercholesterolemic rats. J Nutr 73:299-307.

28. Quazi S, Mohiduzzaman M, Mostafizur Rahman M, Keramat Ali SM (1994) Effect of hilsa (Tenualosa ilisha) fish in hypercholesterolemic subjects. Bangladesh Med Res Counc Bull 20: 1-7.

29. Baraket A, Lamiaa A (2011) Hypolipdemic and anti atherogenic effects of dietary chitosan and wheat bran in high fat-high cholesterol fed rats. Australian J Basic App Sci 107: 656- 663.

30. Makni M, Fetoui H, Gargouri NK, Garoui el M, Jaber H, et al. (2008) Hypolipidemic and hepatoprotective effects of flax and pumpkin seed mixture rich in omega- 3 and omega- 6 fatty acids in hypercholesterolemic rats. Food Chem Toxicol 46: 3714-3720.

31. Ahmed G, Hossain MS, Kabir Y, Jahan SS (2006) Effects of Hilsa llisha fish oil, soybean and palm oil on the serum and liver lipids of experimentally-induced hypercholesterolemic rats. Pak J Med Res. 45: 53-58.

32. Ross R (1999) Atherosclerosis--an inflammatory disease. N Engl J Med 340 115-126. 